\title{
A Study on Preconditions Setting of Long-Term Contract between Manufacturer and Component Supplier
}

\author{
Sidi Wu and Hisashi Onari \\ Dept. of Industrial \& Management Systems Engineering, Faculty of Science \& Engineering, Waseda University, Tokyo 169-8555, Japan
}

\begin{abstract}
To provide a risk-sharing mechanism that encourages a component supplier and a manufacturer to expand their production capacity of components and products, many researches on SCM suggested that it is better for the SC players to connect a long-term contract with flexible preconditions before doing the decision-making of production capacity. With considering of the uncertainty of demand and integrity problems between SC players, it is difficult to set reasonable preconditions. As a result, under-investment problems still occur frequently. In this paper, after we had discussed the decision-making of production capacity with the preconditions by analyzing the character of the players, we verified the under-investment problem of the supply chain. In order to clarify the optimum preconditions to alleviate the under-investment problem, we also analyzed the relations between preconditions and supply capacity of the whole supply chain. In the last part of this paper, we proposed a method of preconditions setting in such uncertain situations.
\end{abstract}

Key words: Supply chain management, production capacity, contract, under investment.

\section{Introduction}

In this paper, we focus on the under-investment problem in a supply chain that consists of an assembly manufacturer and his subcontract component supplier. The manufacturer and the component supplier are planning their production capacity of new products and new components for next term. The component is a key part of the new product, such as the liquid crystal display panel, automotive motor and so on. It only can be purchased from limited suppliers, and product production cannot be in progress without this component. During the decision making of investment planning, high investment cost of production capacity makes the component supplier think about profit acquisition more than risk hedging. Especially, in this kind of supply chain, the under-investment problem of component production capacity occurs frequently.

Corresponding author: Sidi $\mathrm{Wu}$, research associate, research fields: collaborative decision making, supply chain management, and information sharing.
With considering of the under-investment problem, the assembly manufacturer tends to set a lower production capacity of product to hedge the risk of product over-investment. As a result, supply capacity of products of the whole supply chain becomes lower than the expected level. So, it is difficult for the manufacturer to get the expected share rate in the product market. In order to solve this problem, a long-term sale contract with preconditions such as the minimum trading volume and option trading price has been proposed in many researches before.

With considering of expected profit and expected loss, the manufacturer sets the preconditions of the long-term contract and gives them to the component supplier. Under these preconditions, the supplier and the manufacturer set their production capacity themselves with considering of investment behavior of the opponent player. But it is difficult for the manufacturer to do appropriate decision of preconditions under demand uncertainty. Without the exact demand information and the appropriate 
preconditions from manufacturer, the supplier may consider risk hedging seriously. The less-supply problem of the supply chain cannot be solved effectively.

In this paper, after finished modeling the decision-making of production capacity of the component supplier and the manufacturer, we analyzed the under-investment problem quantitatively. Furthermore, with using the decision-making models, a method of preconditions setting for the manufacturer was proposed. The effectiveness of the proposal was proved by comparing with the supply chain total supply capacity and the production capacity difference between the supply and the manufacturer.

\section{Literature Review}

In this section, we will discuss the studies about long-term sales contracts for decision-making of production capacity setting and preconditions of contracts between supply chain players.

With considering of the uncertainty of trading price in spot market, the decision-making model for each collaboration level of the supplier and the buyer was proposed with using a long term capacity reservation contract and a short term sales contract simultaneously [13]. Effectiveness of the proposal was proved with comparing with the supply chain total profit. In high-tech industry, it is difficult for component suppliers to expand their production capacities with constraints of investment capital. As a result, opportunity loss of whole supply chains occur due to buyers cannot get enough volume of components to meet the needs of product demand. In this kind of situation, a contract called deductible reservation was proposed. Decision-making models of players with the contract were created. Deductible reservation contract was compared with take-or-pay contract by supply chain total profit and profit of each player, the proposed deductible reservation contract was proved as the effectiveness one [3]. The two studies discussed uncertainty of market demand and effectiveness of long term contract while doing decision-making of production capacity setting.

The effectiveness of preconditions was also discussed to hedge risks of demand uncertainty in many studies. Pay-to-delay contract set the trading volume and price to three levels, players will set their production capacity with considering of the preconditions about the level of volume and price [2]. Preconditions make the sales contract more flexible, and supplier and buyer can decide a fixed price of components by negotiation in the first step, trading volume can be adjusted in a decided range in the second step [4].

Many studies proposed a lot of new contract methods and preconditions of contract to hedge supply chain risks, but few studies concerned the way of contract connection and preconditions setting. In this paper, we discussed the process of preconditions setting and production capacity setting. We also proposed the method to get the optimum production of the sales contract.

\section{The Contract}

\subsection{Contract Contents}

The component supplier and the manufacturer are planning the production capacity for next new components and products. In order to hedge risks of demand uncertainty, it is better to decide the trading volume at an early time before production capacity planning. It is also necessary to decide a reference trading price for trading volume in such kind of negotiation.

\subsection{Preconditions}

In this paper, we set the preconditions as Fig. 1. It is a simple structure of option contract in many studies to do risk hedging. The effectiveness has also been proved before.

$Q_{c}$ : Minimum trading quantity (volume)

$P_{c}$ : Price per unit of $Q_{c}$

$P_{e}$ : Price per unit of trading quantity over $Q_{c}$ 


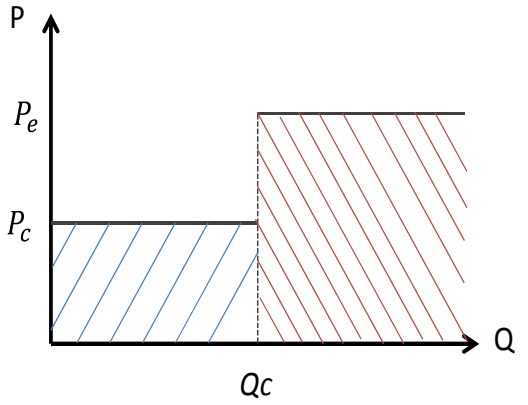

Fig. 1 Contract preconditions.

The supplier and manufacturer should decide their production capacity with considering of the three parameters which were set by the manufacturer. In the next section, we will discuss the method of preconditions setting.

\section{Preconditions Setting}

\subsection{Demand Uncertainty}

The demand of new products in the product market in next several years is uncertain. In this paper, we defined the demand uncertainty as the product demand fluctuations with a product price. The demand is not the whole demand of product market, just the product demand to the manufacturer. We considered the product demand follows a probability distribution. It will fluctuate within a certain range by the intermediate value. To describe the demand uncertainty, PQ curve were used to show the relation between demand and market price. It is a long-term capacity investment, so the trading period was set to about 5 years. Fig. 2a shows the demand uncertainty and Fig. 2b shows the definition of risks. Excess investment risk and opportunity loss risk are taken into consideration when the production capacity was decided.

\subsection{Preconditions Evaluation}

The purpose of preconditions setting of manufacturer is to improve investment incentives of supplier. It is necessary for manufacturer to set preconditions with considering of investment behavior and the characteristics of supplier. Value of expected profit
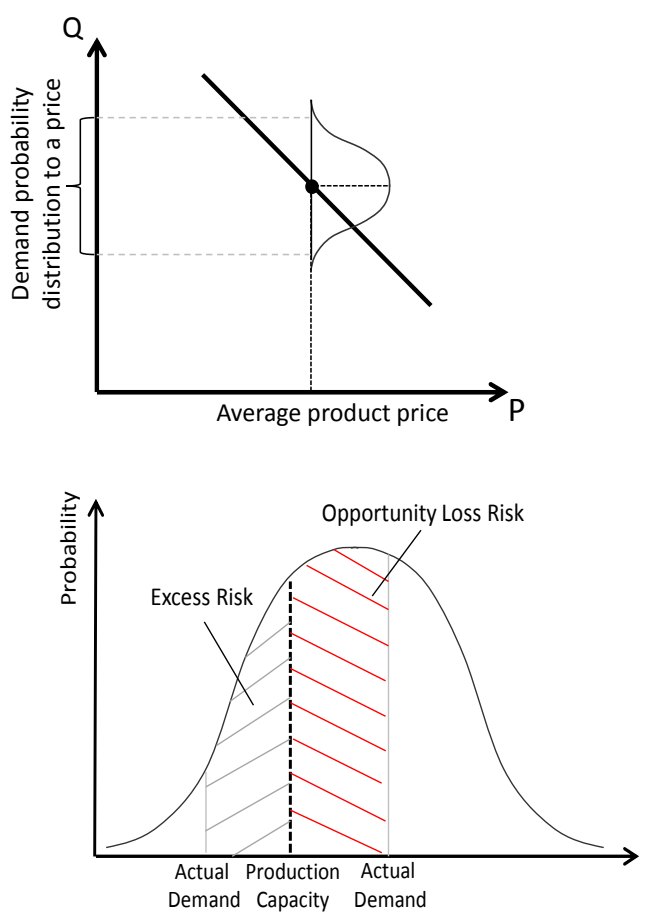

Fig. 2 (a) Demand uncertainty; and (b) risk definition.

and expected loss were calculated with one production capacity by the manufacturer. The manufacturer should know the supplier's attitude (evaluation result) to the expected profit and expected loss in order to set proper preconditions of contract. We use the value function of prospect theory to describe the evaluation value of supplier. Formula 1 shows the value function.

$\mathrm{V}(\mathrm{X}) \Rightarrow\left\{\begin{array}{c}\text { Profit }^{\alpha} \\ -\lambda\left(- \text { Loss }^{\beta}\right.\end{array}(\right.$ Profit $\geq 0$, Loss $<0)$

$\alpha, \beta, \lambda$ are the characteristic parameters of players. With using of value function, the uncertainty of the other player's investment behavior can be quantified.

\subsection{Minimum Trading Quantity $Q_{c}$ Setting}

The purpose of $Q_{c}$ setting of manufacturer is to hedge the risks of components supply shortage in the future and the price rising. After finished demand forecast, the manufacturer will do the calculation of expected profit and expected loss to decide $Q_{c}$. The biggest total value of expected profit and expected loss can be calculated by the production capacity of $Q_{c}$.

Setting procedure of $Q_{c}$ : 
Step1. Forecast the market demand of the new product with considering of the market demand information of existing products;

Step2. Create the PQ curve and demand distribution of average price;

Step3. Calculate the expected profit and expected loss of each demand value from demand distribution. The following two cases are taken into consideration.

Case 1: $\left(Q^{\prime} \leq q\right)$

Expected Profit $=\left[Q^{\prime} p_{a}-I\left(Q^{\prime}\right)-C\left(Q^{\prime}\right)\right]$

$$
\times \int_{Q^{\prime}}^{Q_{\max }} f(Q) d Q
$$

$$
\begin{aligned}
\text { Expected Loss } & =\left[\left(q-Q^{\prime}\right) p_{a}-I(q)-C(q)\right] \\
& \times \int_{Q^{\prime}}^{q} f(Q) d Q
\end{aligned}
$$

Case 2: $\left(Q^{\prime}>q\right)$

$$
\begin{gathered}
\text { Expected Profit }= \\
{\left[q p_{a}-I(q)-C(q)\right] \times \int_{q}^{Q_{\max }} f(Q) d Q} \\
\text { Expected Loss }=\left[\left(Q^{\prime}\right) p_{a}-I(q)-C(q)\right] \\
\times \int_{q}^{Q^{\prime}} f(Q) d Q
\end{gathered}
$$

$q$ : Actual demand;

I: Investment Cost;

$p_{a}$ : Average price of product;

$C$ : Production Cost;

Step4. Use value function to do the calculation of total value about the expected profit and the expected loss.

Step5. Find out the $Q^{\prime}$ with the max total value of the expected profit and the expected loss, set this $Q^{\prime}$ as $Q_{c}$.

$$
V\left(Q_{c}\right)=\operatorname{Max}\left(V_{\text {profit }}\left(Q^{\prime}\right)+V_{\text {loss }}\left(Q^{\prime}\right)\right)
$$

It is necessary to decide $p_{c}$ and $p_{e}$ after finished setting of $Q_{c}$. From step 5, we will show the decision-making process of $p_{c}$ and $p_{e}$.

Step6. Manufacturer should set the desired profit by himself which is a part of the gross profit of supply chain. We set the desired profit rate as $K$.

$$
\begin{gathered}
S C \text { gross profit }= \\
Q_{a} p_{a}-I_{b}(Q)-I_{S}(Q)-C_{b}(Q)-C_{S}(Q)
\end{gathered}
$$

$$
\begin{gathered}
\text { Desired profit }=K\left(Q_{a} p_{a}-I_{b}(Q)-I_{s}(Q)-\right. \\
\left.C_{b}(Q)-C_{s}(Q)\right)
\end{gathered}
$$

$K$ will not get changed though the manufacturer faces the worst situation. The worst situation to the manufacturer is that he can only get component volume $Q_{c}$ from the supplier.

$$
\begin{gathered}
\text { Desired profit }=K\left(\begin{array}{c}
Q_{a} p_{a}-I_{b}(Q)-I_{s}(Q)- \\
C_{b}(Q)-C_{S}(Q)
\end{array}\right) \\
=Q_{c} \times p_{a}-Q_{c} \times p_{c}-I_{b}\left(Q_{c}\right)-C_{b}\left(Q_{c}\right)
\end{gathered}
$$

If the actual demand was the average demand of product market, profit of supplier could be expected by manufacturer with next formula.

$$
\begin{aligned}
& \text { Expected profit of supplier }=(1-K)\left(Q_{a} p_{a}-\right. \\
& \left.\quad I_{b}\left(Q_{c}\right)-I_{s}\left(Q_{c}\right)-C_{b}\left(Q_{c}\right)-C_{s}\left(Q_{c}\right)\right) \\
& =\left(Q_{a}-Q_{c}\right) p_{e}+Q_{c} p_{c}-I_{s}\left(Q_{a}\right)-C_{s}\left(Q_{a}\right)
\end{aligned}
$$

Step7. Calculate $p_{c}$ and $p_{e}$ by formula (9) and (10).

$$
\begin{gathered}
p_{c}=\left(\left(Q_{c}-K Q_{a}\right) p_{a}+(K-1)\left(I_{b}\left(Q_{a}\right)+C_{b}\left(Q_{a}\right)\right)\right. \\
\left.+K\left(I_{s}\left(Q_{a}\right)+C_{s}\left(Q_{a}\right)\right)\right) / Q_{c} \\
p_{e}=\left((1-2 K) Q_{a} p_{a}-Q_{c} p_{a}\right) / Q_{a}-Q_{c}
\end{gathered}
$$

$I_{s}$ : Investment cost of supplier; $I_{b}$ : Investment cost of manufacturer;

$Q_{a}$ : Average demand to average price in the product market;

$C_{s}$ : Production cost of supplier; $C_{b}$ : Production cost of manufacturer

The manufacturer will pass the preconditions to the supplier. The manufacturer will also decide his production capacity with the preconditions himself. We will discuss the production capacity of supplier and manufacturer in next section.

\section{Decision-Making of Production Capacity Setting}

5.1 Decision-Making of Production Capacity Setting by Manufacturer

The manufacturer will set his production capacity for new products with considering of the preconditions of contract. He will choose capacity $Q_{b}$ which can reach the max value of total amount of expected profit and expected loss, and set it as his max 
production capacity. Eq. (13) shows the objective function of the manufacturer.

$$
\begin{gathered}
E\left(Q_{b}\right)=\operatorname{Max}\left(\operatorname{Profit}\left(Q_{b}\right)+\operatorname{Loss}\left(Q_{b}\right)\right) \\
\text { Sub to: } Q_{b} \geq Q_{c}
\end{gathered}
$$

As shown in Fig. 2b, the following two cases of the actual demand are taken into consideration by the manufacturer.

Case 1: $\left(Q_{b} \leq q\right)$

$$
\begin{gathered}
\text { Expected Profit }= \\
{\left[\left(Q_{b}-Q_{c}\right) p_{e}+Q_{c} p_{c}-I_{b}\left(Q_{b}\right)-C_{b}\left(Q_{b}\right)\right] \times} \\
\int_{Q_{b}}^{Q_{\max }} f(Q) d Q
\end{gathered}
$$

Expected Loss $=\left[\left(q-Q_{b}\right) p_{e}-I_{b}\left(Q_{b}\right)-C_{b}\left(Q_{b}\right)\right]$

$$
\times \int_{Q_{b}}^{q} f(Q) d Q
$$

Case 2: $\left(Q_{b}>q\right)$

Expected Profit $=\left[Q_{c} p_{c}+\left(q-Q_{c}\right) p_{e}-I_{b}\left(Q_{b}\right)\right.$

$$
\left.-C_{b}\left(Q_{b}\right)\right] \times \int_{q}^{Q_{\max }} f(Q) d Q
$$

Expected Loss $=\left[\left(Q_{b}-q\right) p_{e}-I_{b}\left(Q_{b}\right)-C_{b}\left(Q_{b}\right)\right] \times$

$$
\int_{q}^{Q_{b}} f(Q) d Q
$$

$q$ : Actual demand; $Q_{b}$ : Candidate max production capacity of manufacturer.

\subsection{Decision-Making of Production Capacity Setting} by Supplier

After getting the preconditions from manufacturer, the component supplier will set his new component production capacity without the latest demand information of product market. Because component suppliers are far from the product market, information asymmetry occurs easily without supply chain collaboration. As the same as the manufacturer, the component supplier will choose capacity $Q_{\mathrm{c}}$ which can reach the max value of total amount of expected profit and expected loss from the demand distribution forecasted by himself, and set it as his max production capacity. Eq. (18) shows the objective function of the supplier.

$$
\begin{gathered}
E\left(Q_{s}\right)=\operatorname{Max}\left(\operatorname{Profit}\left(Q_{s}\right)+\operatorname{Loss}\left(Q_{s}\right)\right) \\
\text { Sub to: } Q_{s} \geq Q_{c}
\end{gathered}
$$
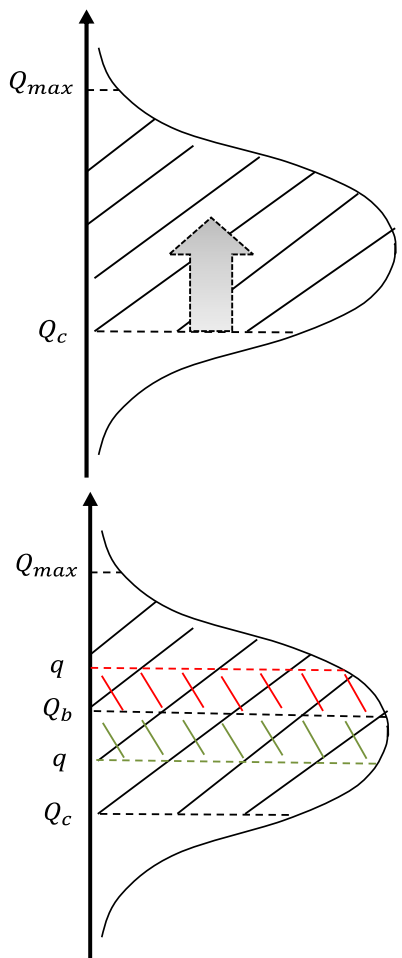

Fig. 3 (a) Range of $Q_{b}$; and (b) Actual demand and $Q_{b}$.

As shown in Fig. 3b, the following three cases of the actual demand are taken into consideration by the manufacturer. Comparing with Fig. 2b, without the exact demand information, the component supplier may consider the case of $q \leq Q_{c}$.

Case 1: $\left(Q_{c}<Q_{s} \leq q\right)$

Expected Profit $=\left[\left(Q_{s}-Q_{c}\right) p_{e}+Q_{c} p_{c}-I_{s}\left(Q_{s}\right)-\right.$

$$
\left.C_{s}\left(Q_{s}\right)\right] \times \int_{Q_{s}}^{Q_{\max }} f(Q) d Q
$$

Expected Loss $=\left[\left(q-Q_{S}\right) p_{e}-I_{S}\left(Q_{S}\right)-C_{S}\left(Q_{S}\right)\right] \times$

$$
\int_{Q_{s}}^{q} f(Q) d Q
$$

Case 2: $\left(Q_{c}<q<Q_{S}\right)$

Expected Profit $=\left[Q_{c} p_{c}+\left(q-Q_{s}\right) p_{e}-I_{s}\left(Q_{s}\right)-\right.$

$$
\left.C_{s}\left(Q_{s}\right)\right] \times \int_{q}^{Q_{\max }} f(Q) d Q
$$

Expected Loss $=\left[\left(Q_{s}-q\right) p_{e}-I_{S}\left(Q_{s}\right)\right] \times \int_{Q_{s}}^{q} f(Q) d Q$

Case 3: $\left(q<Q_{c} \leq Q_{s}\right)$

$$
\text { Expected Profit }=\left[Q_{c} p_{c}-I_{s}\left(Q_{s}\right)-C_{s}\left(Q_{s}\right)\right] \times
$$

$$
\int_{Q_{c}}^{Q_{\max }} f(Q) d Q
$$




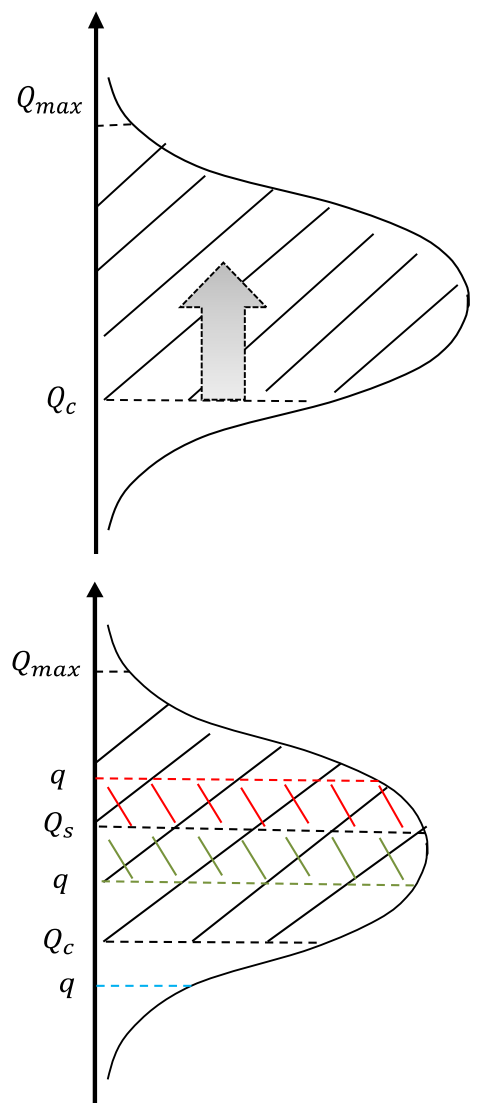

Fig. 4 (a) Range of $Q_{s}$; and (b) Actual demand and $Q_{s}$.

Expected Loss $=\left[\left(Q_{s}-q\right) p_{c}-I_{s}\left(Q_{s}\right)\right] \times \int_{q}^{Q_{s}} f(Q) d Q$

$q$ : Actual demand; $Q_{S}$ : Candidate max production capacity of supplier.

\section{The Experiment}

In this section, we will discuss the experiment of this paper.

Before the experiment, it is necessary to reveal two things. First one is optimum supply capacity, and the second one is player characteristics setting. We consider the optimum supply capacity of supply chain as the production capacity of components and products that set by one player, the manufacturer. In other words, the supply chain is integrated. In this situation setting, there is no need to consider the opponent player's investment behavior. We have discussed the supply chain players before. The component supplier is a subcontractor of the manufacturer, so he may evaluate loss more serious than the manufacturer. We set the parameters of value function as following table.

\subsection{Experiment Plan}

Firstly, we compare the supply capacity setting with preconditions and without preconditions to confirm the effectiveness of the preconditions. Secondly, we do the analysis about the relation between the desired profit rate $K$ of manufacturer and the whole supply capacity of this supply chain. Thirdly, we analyze the relation between the desired profit rate $K$ and the preconditions. At last, we discuss the difference between production capacity of supplier and manufacturer with the desired profit rate $K$.

\subsection{The Results}

In the following section, we analyze the result of simulation based on simulator which was developed by VBA.

Fig. 4 shows the production capacity of supplier and manufacturer with preconditions and without preconditions comparing with the optimum supply capacity. We confirmed the effectiveness of preconditions of contract while doing the decision-making of production capacity. We also found the difference between production capacity of the component supplier and the assembly manufacturer is less with using of preconditions.

Fig. 5 shows the relation between desired profit rate and SC supply capacity. The higher expected profit rate setting of manufacturer, the probability of achieving the optimal production capacity is also higher. We found that it is not better to cede the profit to the supplier during the decision-making of preconditions setting. While the manufacturer planning to propose preconditions of contract to the supplier before the

Table 1

\begin{tabular}{lll}
\hline & Supplier & Manufacturer \\
\hline$\alpha$ & 0.3 & 0.4 \\
$\beta$ & 0.4 & 0.2 \\
$\lambda$ & 2.5 & 1.5 \\
\hline
\end{tabular}




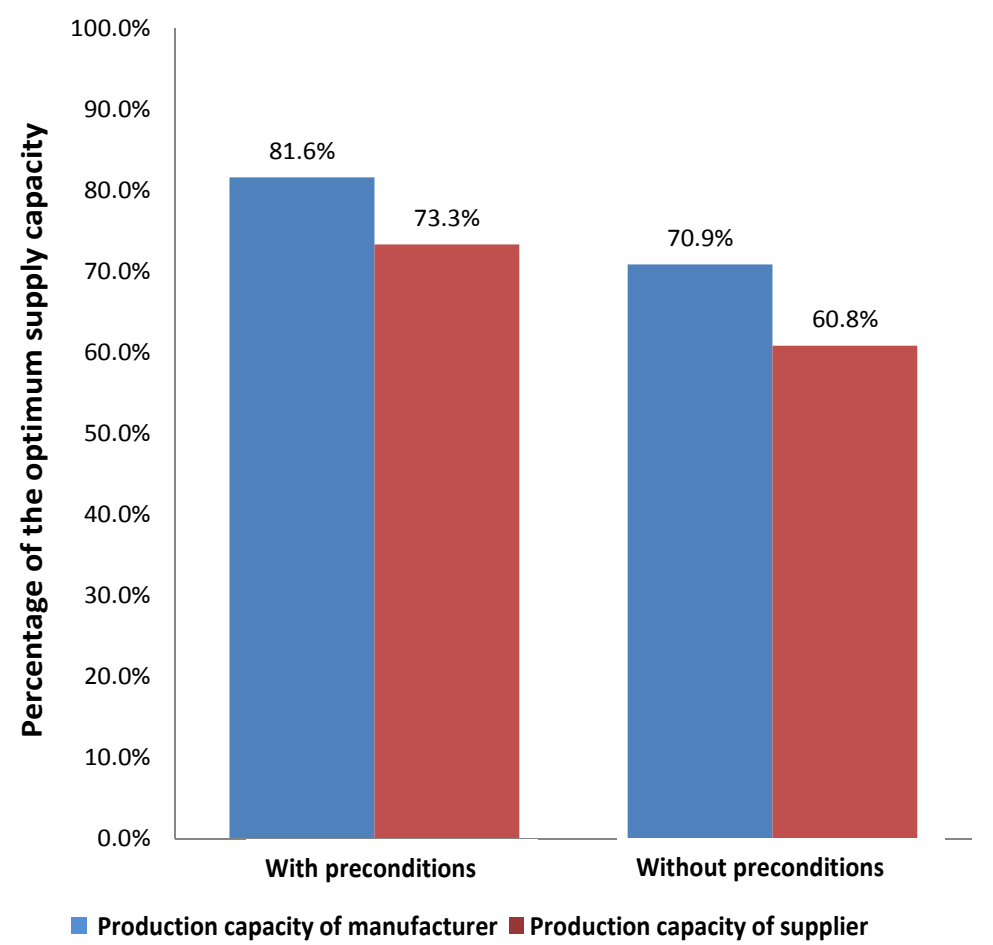

Fig. 5 Production capacity setting of supplier and manufacturer with preconditions and without preconditions.

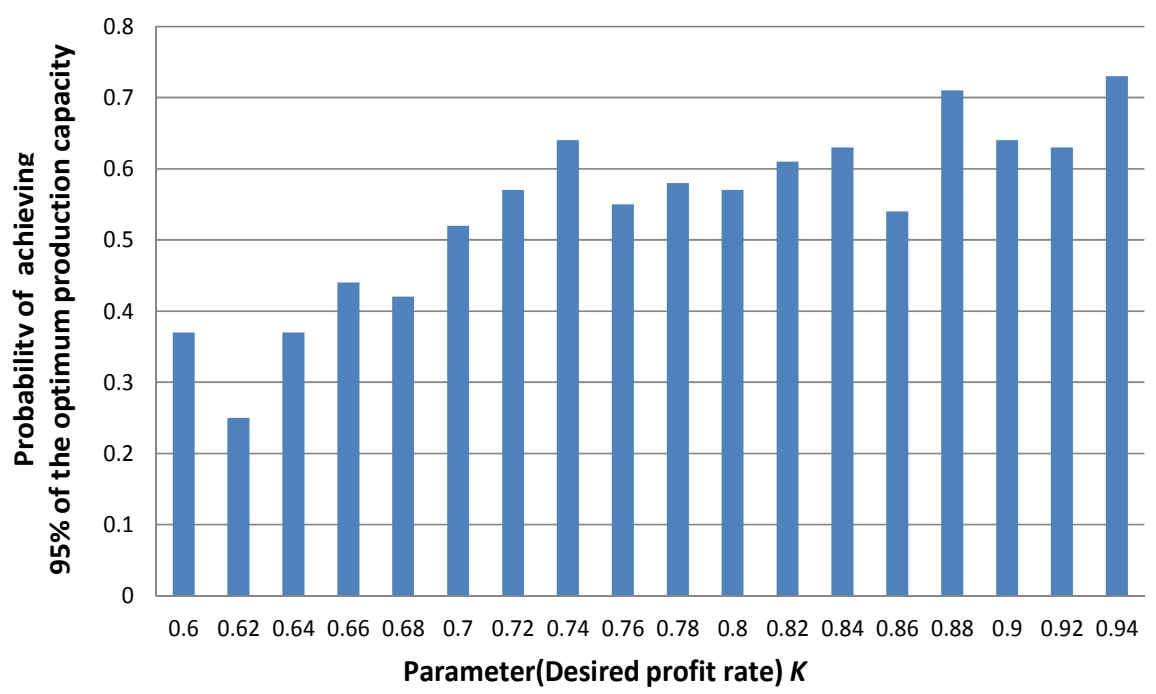

Fig. 6 Relation between $\mathrm{K}$ and supply capacity.

production capacity setting, just to set a higher profit rate himself, and it may make the component supplier do investment positively. As a result, it can help the supply chain to reach a higher supply capacity so as to achieve more profit for both players.

As shown in Fig. 6, we discuss the desired profit rate and the precondition $p_{e}$ and $p_{c}$. The larger difference between $p_{e}$ and $p_{c}$, the SC supply capacity is higher. The reason is that large difference between $p_{e}$ and $p_{c}$ may improve the investment incentive of component supplier. During the decision-making of preconditions setting, it is better for the manufacturer to set a higher value of $K$ to make the difference of $p_{e}$ and $p_{c}$ large. The manufacturer may get a little 


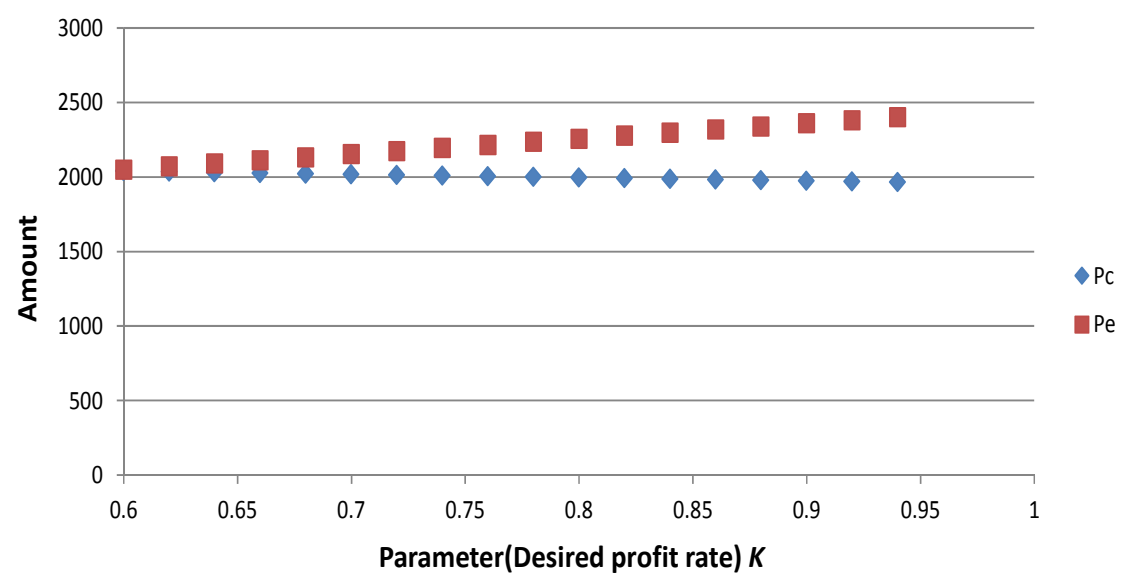

Fig. 7 Relation between $K$ and preconditions of $p_{e} p_{c}$.

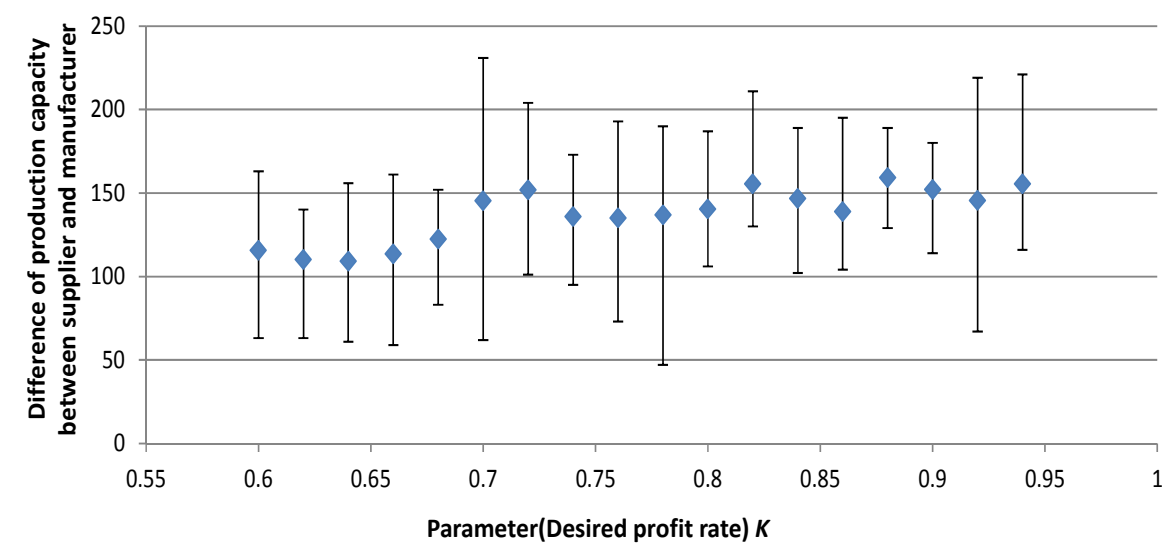

Fig. 8 Relation between $K$ and production capacity difference.

loss with his profit achieving, however it can help the manufacturer to hedge risks.

Fig. 7 shows the relation between $K$ and the production capacity of supplier and manufacturer. We analyzed the average value, range and standard deviation of the difference of production capacity between supplier and manufacturer with different value of $K$. From Fig. 8, we found that higher expected profit rate may make the difference of production capacity large.

But there is no significant relation between the standard deviation of production capacity difference and the expected profit rate $K$.

\section{Conclusions}

In this paper, we designed the manufacturer's decision-making model of preconditions setting of the long-term sales contract during the decision-making of production capacity setting of the two supply chain players. We set the preconditions as minimum trading quantity, price of minimum trading quantity and price of trading quantity over minimum trading quantity. We also designed decision-making model of production capacity setting of the supplier and the manufacturer with considering of the preconditions. We proved the effectiveness of under-investment improvement with using of the preconditions quantitatively. Supply chain over-investment problem (production capacity difference between supplier and manufacturer) could also be improved by the preconditions. We found that the larger difference between $p_{e}$ and $p_{c}$, component supplier's 
investment incentive becomes higher. It can improve the SC under-investment problem. From the simulation result, we found that the setting of the price of trading quantity over minimum trading quantity is more important than the price of minimum trading quantity. Because of the price $p_{e}$ which may affect the SC supply capacity more sensitive. From this paper, during decision-making of preconditions setting, it is an incorrect way to reduce the expected profit rate to make more SC supply capacity in such situation. It seems a better way to share the supply chain total profit. But a lower expected profit rate may make the supplier's investment incentive lower.

In this paper, we used the value function to show the characteristics of supply chain players. But we did not show how to set the characteristics parameters with considering of investment behavior of the opponent. We will finish the model of uncertainty of opponent's investment behavior in the near future to improve this paper.

\section{References}

[1] Van Mieghem, J. A. 1999. "Coordinating Investment, Production and Subcontracting." Management Science 45 (7): 954-71.

[2] Wu, J. 2006. "Risk Analysis of a Pay to Delay Capacity Reservation Contract." Optimization Methods and Software 21: 635-51.

[3] Jin, M. Z. 2007. "Capacity Reservation Contracts for High-Tech Industry." European Journal of Operational Research 176: 1659-77.

[4] Deng, S. M., and Yano, C. A. 2002. "On the Role of a Second Purchase Oportunity in a Two-Echelon Supply Chain." Working Paper, Department of Industrial Engineering and Operations Research, Uninversity of California, Nerkeley, CA.

[5] Chen, P. Y. 2011. "The Investment Strategies for a Dynamic Supply Chain under Stochastic Demands." Int. J. Production Economics 139: 80-9..

[6] Callen, J. L., and Sarath, B. 1995. "Risk Aversion, Generalized Correlation and Investment in Manufacturing Capacities." Journal of Operations Management 12: 225-37.

[7] Renna, P., and Argoneto, P. 2012. "Capacity Investment Decision in Co-opetitive Network by Information
Sharing." Computer \& Industrial Engineering 62: 359-67.

[8] Marquez, A. C., and Blanchar, C. 2006. "A Decision Support System for Evaluating Operations Investment in High-Technology Business." Decision Support Systems 41: 472-87.

[9] Gerchak, Y., and Wang, Y. Z. 2004. "Revenue-Sharing vs. Wholesale-Price Contracts in Assembly Systems with Random Demand." Production and Operations Management 12 (1): 23-33.

[10] Banerjee, A. 2005. "Concurrent Pricing and Lot Sizing for Make-to-Order Contract Production." Int. J. Production Economic 93-94: 189-95.

[11] Hazra, J., and Mahadevan, B. 2009. "A Procurement Model Using Capacity Reservation.” European Journal of Operational Research 193: 303-16.

[12] Mathur, P. P., and Shah, J. 2008. "Supply Chain Contracts with Capacity Investment Decision: Two-Way Penalties for Coordination.” Int. J. Production Economics 114: $56-70$.

[13] Inderfurth, K., and Kelle, P. 2011. "Capacity Reservation under Spot Market Price Uncertainty.” Int. J. Production Economics 133: 272-9.

[14] Cachon, G. P., and Lariviere, M. A. 2001. "Contracting to Assure Supply: How to Share Demand Forecasts in a Supply Chain." Management Science 47 (5): 629-46.

[15] Serel, D. A., Dada, M., and Moskowitz, H. 2001. "Sourcing Decisions with Capacity Reservation Contracts." European Journal of Operational Research 131: 635-48.

[16] Brown, A. O., and Lee, H. L. 1997. "Optimal 'Pay to Delay' Capacity Reservation with Application to the Semiconductore Industry." Working Paper, Stranford University, Stanford, CA, November 8. 1-25..

[17] Harrison, J. M., and Van Mieghem, J. A. 1999. "Multi-resource Investment Strategies: Operational Hedging under Demand Uncertainty." European Journal of Operational Research 113: 17-29.

[18] Tsay, A. A. 1996. "The Quantity Flexibility Contract and Supplier-Customer Incentives." Working Paper, Stanta Clara University, Santa Clara, CA.

[19] Bakos, J. Y., and Brynjolfsson, E. 1993. "Information Technology, Incentives and the Optimal Number of Suppliers." Journal of Management Information Systems. 10 (2): 37-53.

[20] Kleindorfer, P., and Wu, D. J. 2003. "Intergrating Long-Term and Short-Term Contracting via Business-to-Business Exchanges for Capital Intensive Industries.” Management Science 49 (11): 1597-615.

[21] Li, C., and Kouvelis, P. 1999. "Flexible and Risk-Sharing Supply Contracts under Price Uncertainty." Mangement Science 45 (10): 1378-98. 
[22] Ojala, M., and Hallikas, J. 2006. "Investment Decision-Making in Supplier Networks: Managment of Risk." International Journal of Production Economics 104: 201-13.

[23] Callen, J. L., and Sarath, B. 1995. "Risk Aversion, Generalized Correlation and Investment in Manufacturing Capacities." Journal of Operations Management 12: 225-37.
[24] Fine, C. H., and Freund, R. M. 1990. "Optimal Investment in Product-Flexible Manufacturing Capacity." Management Science 36: 449-66.

[25] Agrawal, V., and Seshadri, S. 2000. "Impact of Uncertainty and Risk-Averse on Price and Order Quantity in the Newsvendor Problem." Manufacturing and Service Operations Management 2: 410-23. 